\section{DEPOSIÇÃO IRREGULAR DE RESÍDUOS NO LEITO DAS RUAS DE OURINHOS E AUMENTO DAS ENXURRADAS E INUNDAÇÕES}

\author{
Victória Helena Borsa Piroli ${ }^{1}$
}

Edson Luís Piroli ${ }^{2}$

\begin{abstract}
RESUMO
Este trabalho teve como objetivo analisar a presença e quantificar os entulhos dispostos ao longo do eixo de algumas ruas do bairro Jardim Paulista em Ourinhos, SP e dissertar acerca dos problemas que isso acarreta à água e à sociedade no presente e a médio e longo prazo. Para isso foram realizados trabalhos de campo apoiados em um aparelho de GPS de navegação, com registros fotográficos das pilhas de resíduos em 16 quadras, de 11 ruas do bairro, com georreferenciamento das mesmas. Nestes levantamentos foram encontrados depósitos de entulhos em todas as ruas, contabilizando-se 38 montes com os mais diversos tamanhos e com variados tipos de materiais, como resíduos de construção, restos de poda de plantas, sacolas plásticas, papéis, sofás, etc. Observou-se que o problema deriva de um hábito da população que traz transtornos relativos ao entupimento de bocas de lobo e inundações, devendo ser feito um trabalho de conscientização nas residências, nas escolas, centros comunitários, entre outros locais, explicando os problemas e as consequências dessas deposições irregulares. A prefeitura deve também adotar sistemas de coleta semanal, com dia fixo e divulgar à população e além disso, deve ser criada legislação específica para no caso das campanhas de conscientização não surtirem efeito, haver a punição dos indivíduos que descumprirem as normas.
\end{abstract}

PALAVRAS-CHAVE: Entulho. Água. Microbacias.

\section{DUMPING DEBRIS IRREGULAR IN OURINHOS STREETS AND INCREASE OF FLOODING AND FLOODS}

\begin{abstract}
This work aimed to analyze the presence and quantify the debris disposed along the street axis of some streets on the Jardim Paulista neighborhood in Ourinhos, SP and lecture about the problems that it brings to water and society in the present and in the medium and long term. For this were carried out field work supported in a GPS navigation device with photographic records in 16 blocks of 11 streets in the neighborhood with georeferencing of debris. In these surveys, were found deposits in all the streets, that deposits were represented with different sizes and with different types of materials such as debris of construction, pruning waste, plastic bags, paper, sofas, etc. It was observed that the problem derive from a habit of the population that brings disorders related to clogging of manhole and flooding, and should be made an awareness campaign in homes, schools, community centers, among other places, explaining the problems and consequences of irregular deposition, also should the city adopt systems of gathering weekly, with fixed day and disseminate to the public and it should also be created a specific legislation in the case of awareness campaigns have no effect and be settled a punishment of individuals who break the rules.
\end{abstract}

KEYWORDS: Debris, water, watershed.

\footnotetext{
${ }_{1}^{1}$ Graduanda em Geografia pela UNESP- Ourinhos. victoriapiroli@gmail.com.

2 Professor adjunto, UNESP- Ourinhos. piroli@ourinhos.unesp.br
} 


\section{DISPOSICIÓN IRREGULAR DE RESIDUOS EN LA CAMA DE OURINHOS CALLES Y AUMENTO DE INUNDACIONES}

\section{RESUMEN}

Este estudio tuvo como objetivo analizar la presencia y cuantificar los residuos dispuestos a lo largo del eje de algunas de las calles del barrio Jardim Paulista en Ourinhos, SP y escribir sobre los problemas que esto conlleva al agua y sociedad en el presente y en el mediano y largo plazo. Para ello se llevaron a cabo trabajos de campo con un dispositivo de navegación GPS apoyado con registros fotográficos de los residuos en 16 bloques de 11 calles del barrio, con la geo-referencia a ellos. En estas encuestas se encuentran depósitos de escombros en todas las calles, contando 38 montes con diferentes tamaños y con diferentes tipos de materiales, tales como residuos de la construcción, residuos de poda de plantas, bolsas de plástico, papeles, sofás, etc. Se observó que el problema se deriva de la costumbre de la población que trae trastornos relacionados con la obstrucción de las pozo de visita y las inundaciones, se debe hacer una campaña de sensibilización en los hogares, escuelas, centros comunitarios, entre otros lugares, explicando los problemas y consecuencias de depósitos irregulares. La ciudad también debe adoptar sistemas de recogida semanales con día fijo y difundir al público y por otra parte, la legislación específica debe ser creada para el caso de las campañas de sensibilización no tienen ningún efecto, una sanción a los que violan las leyes

PALABRAS CLAVE: Depositos. Agua. Cuencas.

\section{INTRODUÇÃO}

O problema relacionado à agua tem sido cada vez mais grave no mundo todo, com uma intensidade também aumentada no estado de São Paulo, principalmente no ultimo ano. Uma das origens dessa problemática é a pouca infiltração da água das chuvas consequência da alta taxa de impermeabilização de ruas e quintais. $\mathrm{Na}$ cidade de Ourinhos, onde este estudo foi realizado, além desta característica, um dos agravantes ao manejo da agua das chuvas é o habito da população de depositar os mais diversos tipos de resíduos, incluindo entulhos e restos de poda ao longo do eixo das ruas, sendo este material em períodos de chuva transportado pela água até os níveis mais baixos do relevo, entupindo bocas de lobo e potencializando o poder erosivo destas águas. Além disso, as bocas de lobo entupidas acabam direcionando a água aos fundos de vale aumentando as enxurradas e causando inundações. Contribuindo, inclusive, para que ocorra morte de pessoas em períodos de chuvas mais intensas, como aconteceu em setembro de 2014 na área urbana de Ourinhos, no bairro Ouro Verde, quando uma mulher foi arrastada com sua casa para o córrego Monjolinho, tendo seu corpo encontrado mais de dois meses depois, três quilômetros à jusante de sua residência. 


\section{Periádica Eletranica

Destaca-se que além desta morte, ocorreu outra no mês de fevereiro de 2015, no córrego Christoni, onde outra mulher foi arrastada pelas águas que chegaram a grande volume ao córrego canalizado, vindas de uma microbacia quase completamente impermeabilizada e com importante concentração de entulhos e lixo. Um dado que corrobora esta afirmação é o fato de que no momento do arraste da mulher, não chovia no local onde ela se encontrava, mas sim, nas cabeceiras da microbacia.

Essa alta vazão decorre da ampla cimentação das calçadas e dos quintais das casas, nas quais não há a preocupação da manutenção de uma área permeável para absorver a água, levando-a a escorrer superficialmente e em grande quantidade pela rua, sendo direcionada a bocas de lobo, onde estas existem, e quando estão desentupidas. No caso da inexistência ou do entupimento destas, a água escorre para córregos e baixadas, com potencial para inundações. Conforme Piroli (2014) a água que precipita, se não for infiltrada, escorrerá para as regiões mais baixas, e se acumulada superficialmente causa inundações e traz riscos e prejuízos para a comunidade. Para que a água infiltre em quantidades próximas daquelas originalmente infiltradas, quando da cobertura vegetal original, é preciso manter a maior área permeável possível.

Segundo Cadorin e Mello (2011) e Pedron et al. (2004), os solos da cidade, impermeabilizados por cimento e asfalto, têm escoamento superficial e intenso, pois quase toda a água escorre pelas ruas. A urbanização acaba por compactar o solo, diminuindo a porosidade e a infiltração de água, aumentando o escorrimento superficial, de modo que um volume maior de precipitação escorre de forma mais rápida para os cursos de água. Se o sistema de drenagem da cidade não funciona de forma adequada, aumenta o pico de vazão e a potencialidade de enchentes.

Um agravante para essa situação é a deposição irregular de resíduos sólidos, tais como os de construção civil, pois de acordo com Takenaka et al. (2012),

A inadequada disposição final dos resíduos sólidos da construção
civil traz inúmeros problemas ao município, principalmente aqueles
envolvendo impactos ambientais, tais como: degradação das áreas
de manancial e de proteção permanente, proliferação de agentes
transmissores de doenças, assoreamento de rios e córregos,
obstrução dos sistemas de drenagem (galerias, sarjetas, etc.),
ocupação de vias e logradouros públicos por resíduos, com prejuízo
à circulação de pessoas e veículos, além da própria degradação da
paisagem urbana e existência e acúmulo de resíduos que podem
gerar risco por sua periculosidade, p. 181 . 
Além disso, como normalmente os municípios não coletam o entulho gerado, é muito comum o despejo em áreas clandestinas, vias públicas, terrenos baldios e até margens de rios, trazendo diversos transtornos como: a geração de depósitos instáveis passíveis de deslizamentos quando lançados em encostas ou terrenos problemáticos e ou, levando à obstrução do escoamento pluvial e provocando inundação, quando lançado em terras baixas. (TAKENAKA, 2012 apud D'ALMEIDA e VILHENA, 2000).

Conforme Jacob e Besen (2011) o lixo produzido e não coletado é disposto de maneira irregular nas ruas, em rios, córregos e terrenos vazios, e tem efeitos tais como assoreamento de rios e córregos, entupimento de bueiros com consequente aumento de enchentes nas épocas de chuva, além da destruição de áreas verdes, mau cheiro, proliferação de moscas, baratas e ratos, todos com graves consequências diretas ou indiretas para a saúde pública.

Oliveira e Mendes (2008) complementam que na grande maioria dos municípios, a maior parte desse resíduo é depositada em bota-fora clandestino, nas margens de rios e córregos ou em terrenos baldios.

Neste contexto a presente pesquisa foi desenvolvida fundamentada na análise de bacias hidrográficas, com ênfase no manejo de microbacias e de resíduos sólidos urbanos.

\section{OBJETIVOS}

Este trabalho teve como objetivo analisar a presença e quantificar os entulhos dispostos ao longo do eixo de algumas ruas do bairro Jardim Paulista em Ourinhos, $\mathrm{SP}$ e dissertar acerca dos problemas que isso acarreta à água e à sociedade no presente e a médio e longo prazo.

\section{METODOLOGIA}

Nesta pesquisa foram realizados trabalhos de campo apoiados em um aparelho de GPS (Sistema de posicionamento global) de navegação, com registros fotográficos das pilhas de resíduos. Foram percorridas 16 quadras, de 11 ruas do bairro Jardim Paulista, com georreferenciamento dos entulhos. Os registros foram 


\section{Periódica Eletrânica \\ Fórum Ambiental}

da Alta Paulista
Volume 11, Número 06, 2015

\section{Planejamento e Gestão} dos Recursos Hídricos

feitos na tarde do dia 28 de março de 2015, data escolhida aleatoriamente. Posteriormente, os dados da localização dos entulhos foram trabalhados em um SIG (Sistema de Informações Geográficas) para visualização da espacialização dos mesmos. A área de estudo é mostrada na figura 1.

Figura 1- Croqui de localização da área de estudo.
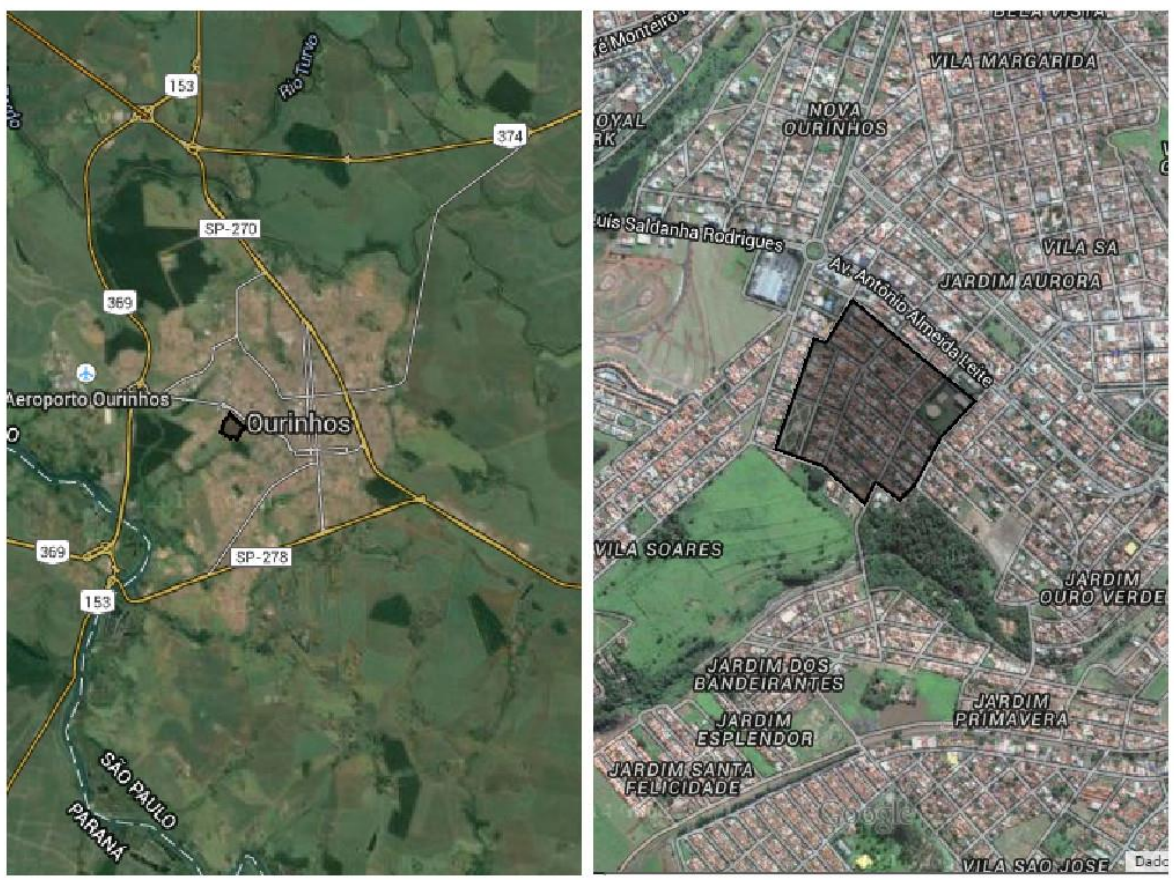

Fonte: Google Earth, 2015. Organização dos autores.

\section{RESULTADOS}

Nos levantamentos realizados na área de estudo, foram encontrados depósitos de entulhos em todas as ruas, contabilizando-se 38 montes com os mais diversos tamanhos e com variados tipos de materiais, como resíduos de construção, restos de poda, sacolas plásticas, papéis, sofás, etc., como se pode observar na figura 2, na qual se pode verificar grande quantidade de folhas e galhos provenientes de podas, depositados nas beiradas das ruas, exatamente no local por onde a água da chuva deve escoar. Pelas avaliações feitas in loco verificou-se que em alguns casos, o material já se encontrava no local há dias ou semanas. 
Figura 2 - Fotografias de galhos e folhas localizados no bairro Jardim Paulista.

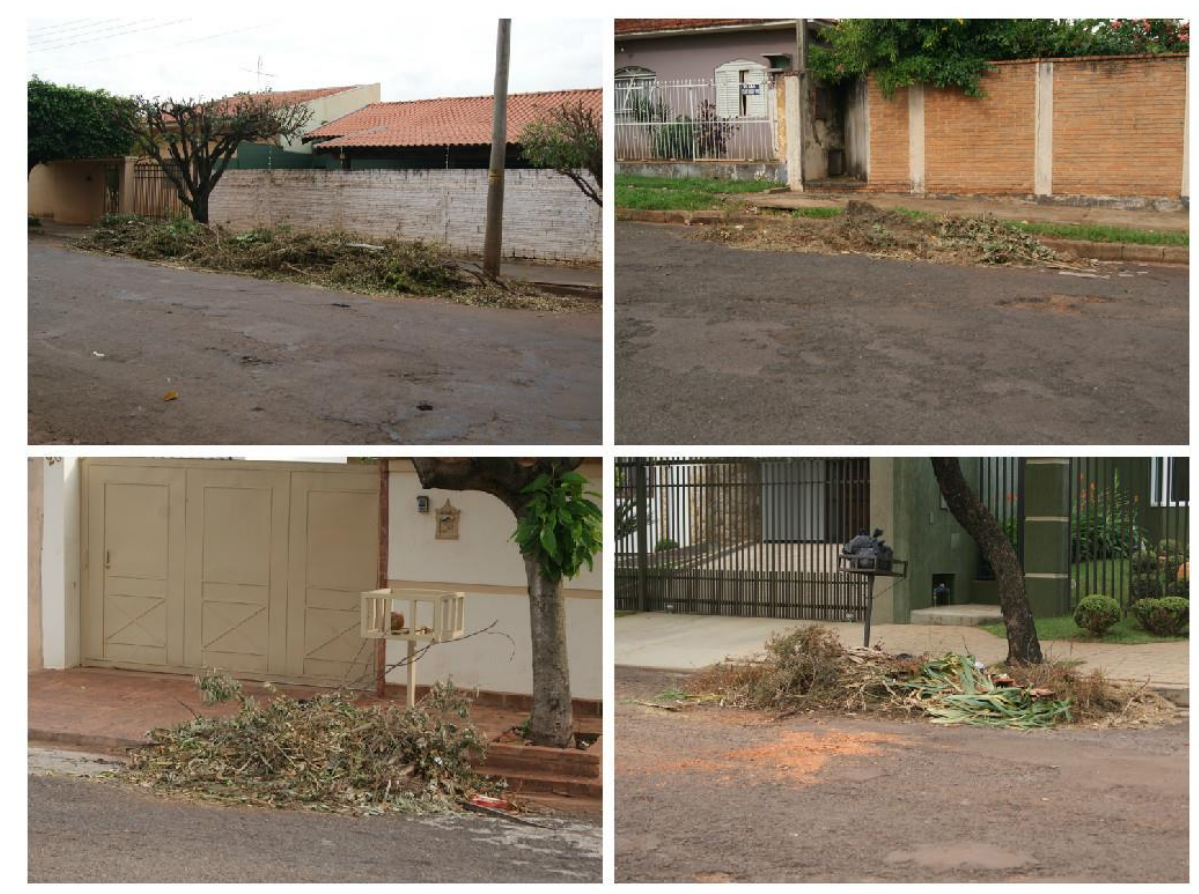

Fotografias dos autores, 2015.

A figura 3 mostra fotografias contendo, além de folhas, galhos e restos de poda, também sacos plásticos, entulhos e resíduos domésticos, que incluem cama e sofá. Também se observou a ausência de lixeiras para acondicionamento de sacos plásticos nas calçadas em frente às residências, o que indica o costume de depósito desse tipo de lixo ao longo da rua, e a cultura de transformar o problema particular em público. Isto confirma o exposto por Tucci (1997) que "à medida que a cidade se urbaniza aumenta a produção de resíduos sólidos o que causa a deterioração da qualidade da água". 
Figura 3 - Fotografias de entulhos e galhos localizados no bairro Jardim Paulista.
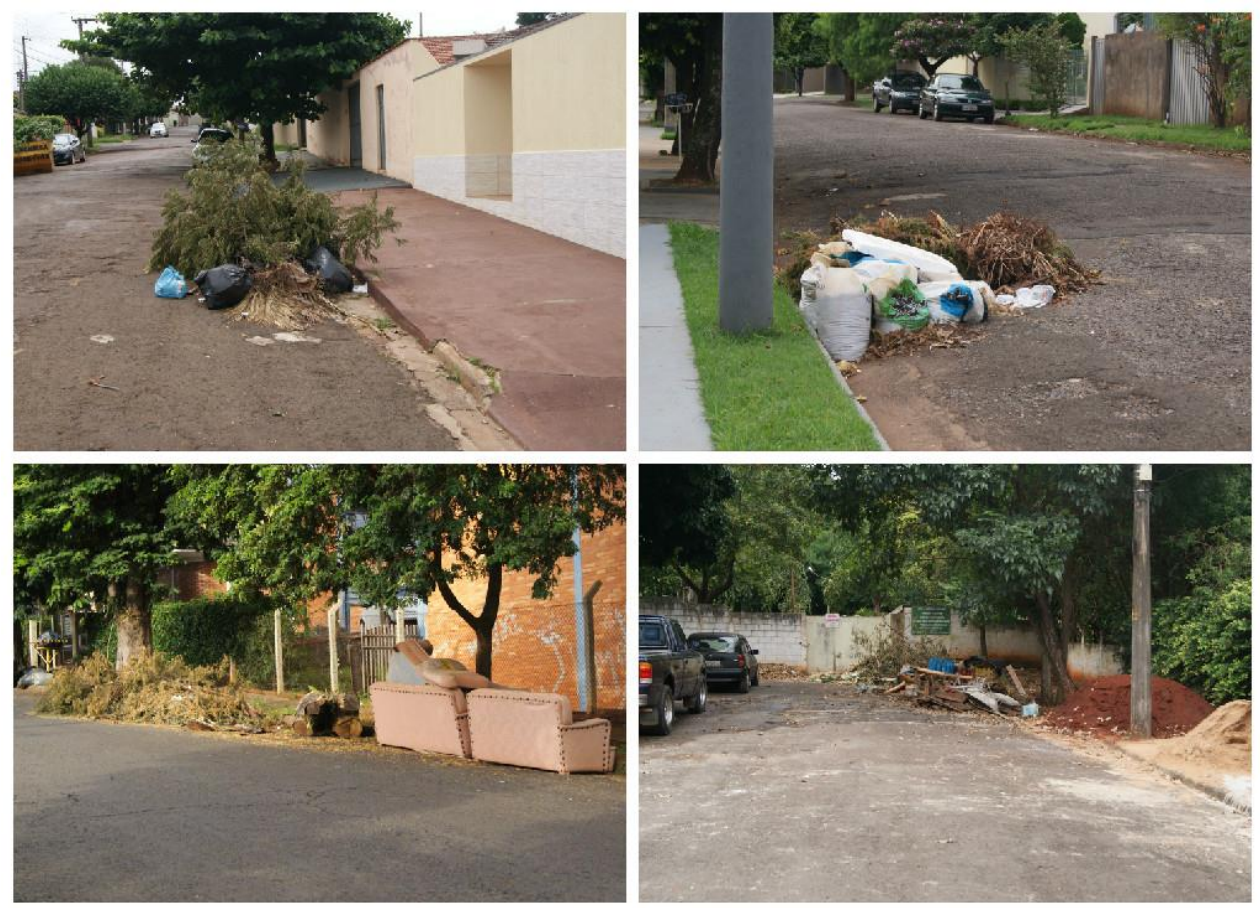

Fotografias dos autores, 2015.

$\mathrm{Na}$ figura 4, além das folhas e galhos, comuns em todas as ruas, encontramse também materiais jogados pelos pedestres, como copos de plástico, papéis e embalagens. Verificou-se que existem montes de entulhos que já se encontram há tanto tempo no eixo da rua que já apresentam grama e ervas daninhas, sendo lugar propício para a proliferação de animais peçonhentos e insetos, como o aedes aegypti, que no verão de 2015 causou inúmeros casos de dengue na área estudada. Este aspecto também é visível nos terrenos baldios existentes no local. 
Figura 4 - Resíduos variados encontrados na área de estudo.
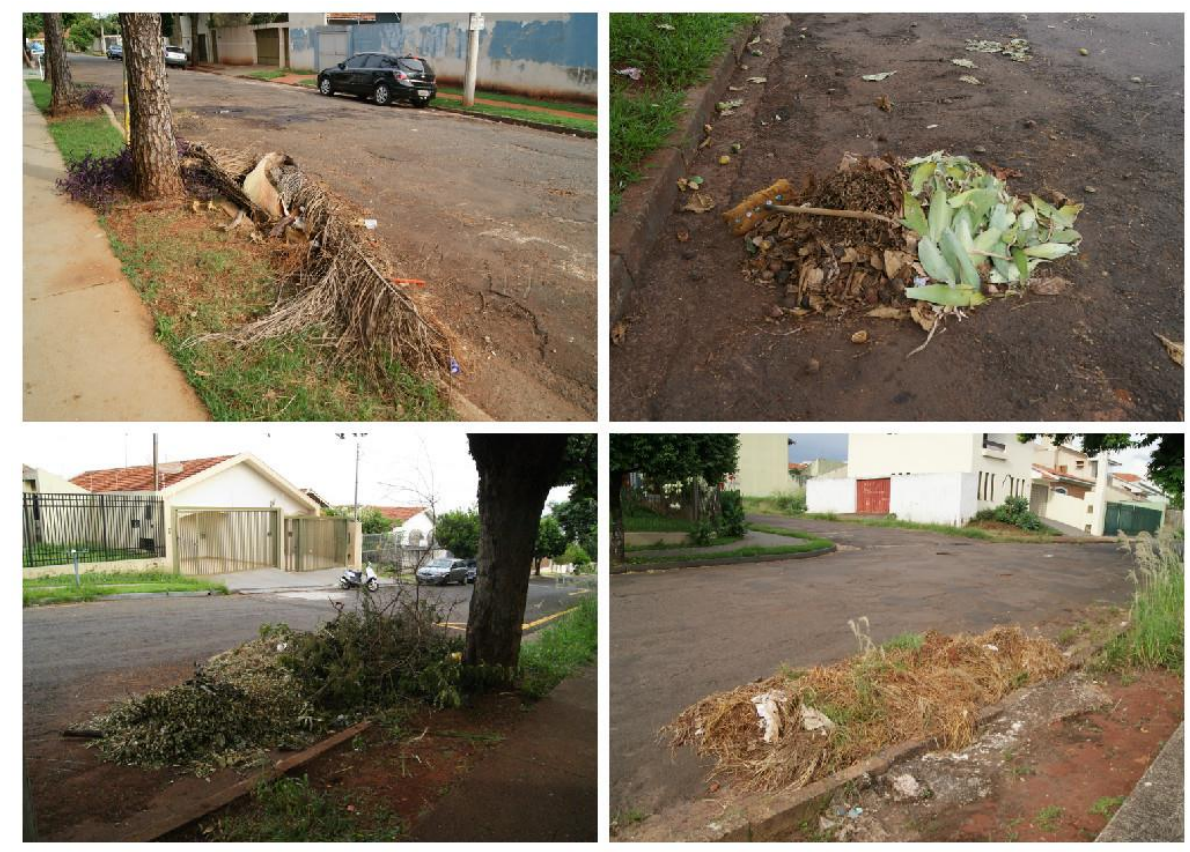

Fotografias dos autores, 2015.

Estas situações também causam problemas como a poluição e a contaminação dos corpos hídricos, com o lixo sendo transportado até o rio, e a proliferação de insetos que se criam nos vasilhames que em dias de chuvas mais fracas se enchem de água e facilitam a eclosão de ovos de várias espécies, como do mosquito da dengue.

$\mathrm{Na}$ figura 5, observam-se dois depósitos muito próximos um do outro, tendo sido feitos por moradores distintos, e contando com o mesmo tipo de material (restos de coleta de lixo e material resultante de podas) evidenciando que o depósito de restos na rua é um hábito da população deste bairro e, também do município de Ourinhos.

A grande quantidade de lixo depositado no eixo das ruas pode derivar em inúmeros problemas tanto na arcada ambiental quanto na arcada social. Na parte ambiental, acarreta entupimentos de bocas de lobo em dias de chuva, o que pode levar a enxurradas nas vertentes, potencializadas em áreas muito íngremes, e 
inundações das regiões mais baixas do relevo. Destaca-se o fato de que as enxurradas e as inundações têm aumentado nos últimos anos, devido à alta taxa de impermeabilização das ruas e dos quintais e à grande quantidade de resíduos e entulhos depositados nas bordas das ruas.

Figura 5 - Dois depósitos de resíduos de poda na mesma rua.

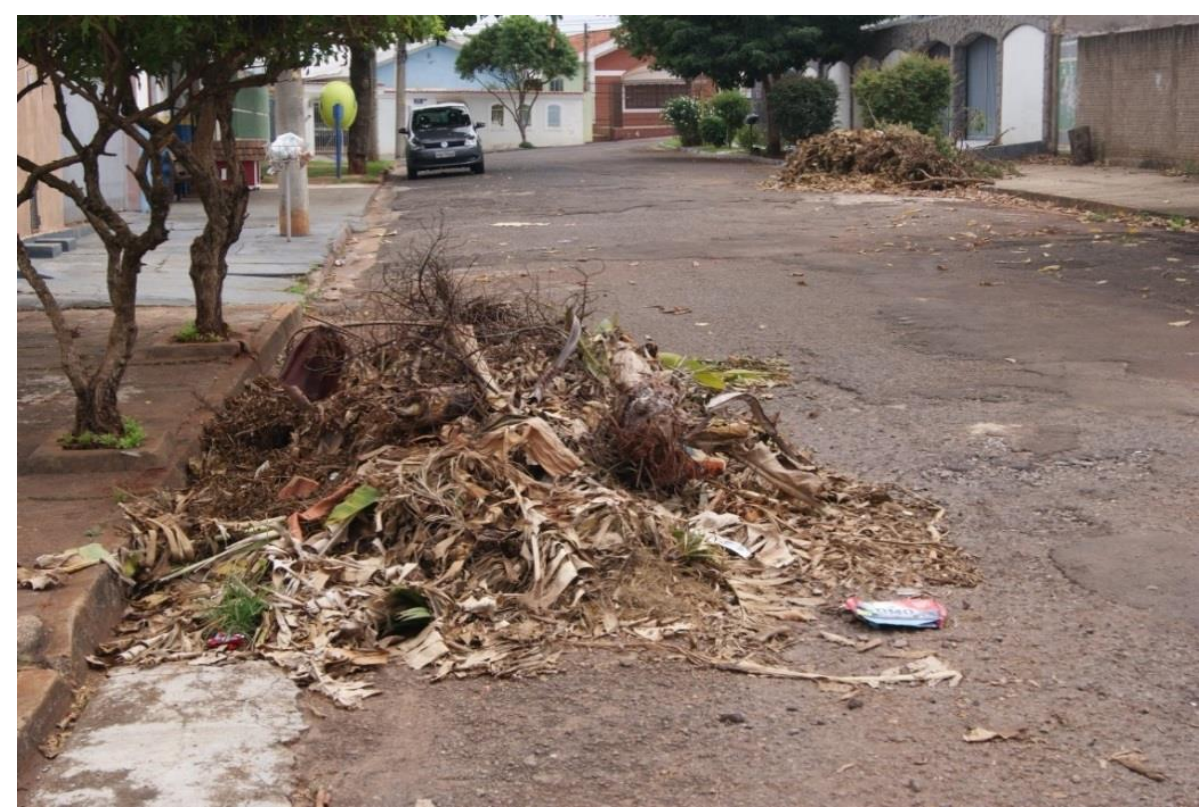

Fotografia dos autores, 2015.

Esta condição tem destruído as estruturas urbanas como asfalto, calçadas e bocas de lobo, conforme pode ser visto na figura 6 . Nela é mostrado que mesmo a prefeitura tendo cimentado parte da rua que foi destruída na chuva de 26 de setembro de 2014, a água acumulada em grande volume continua destruindo a mesma e, atualmente, avança sobre a calçada, cujo material é menos resistente ao poder erosivo da água. 
Figura 6- Calçada destruída pelas chuvas de dezembro de 2014

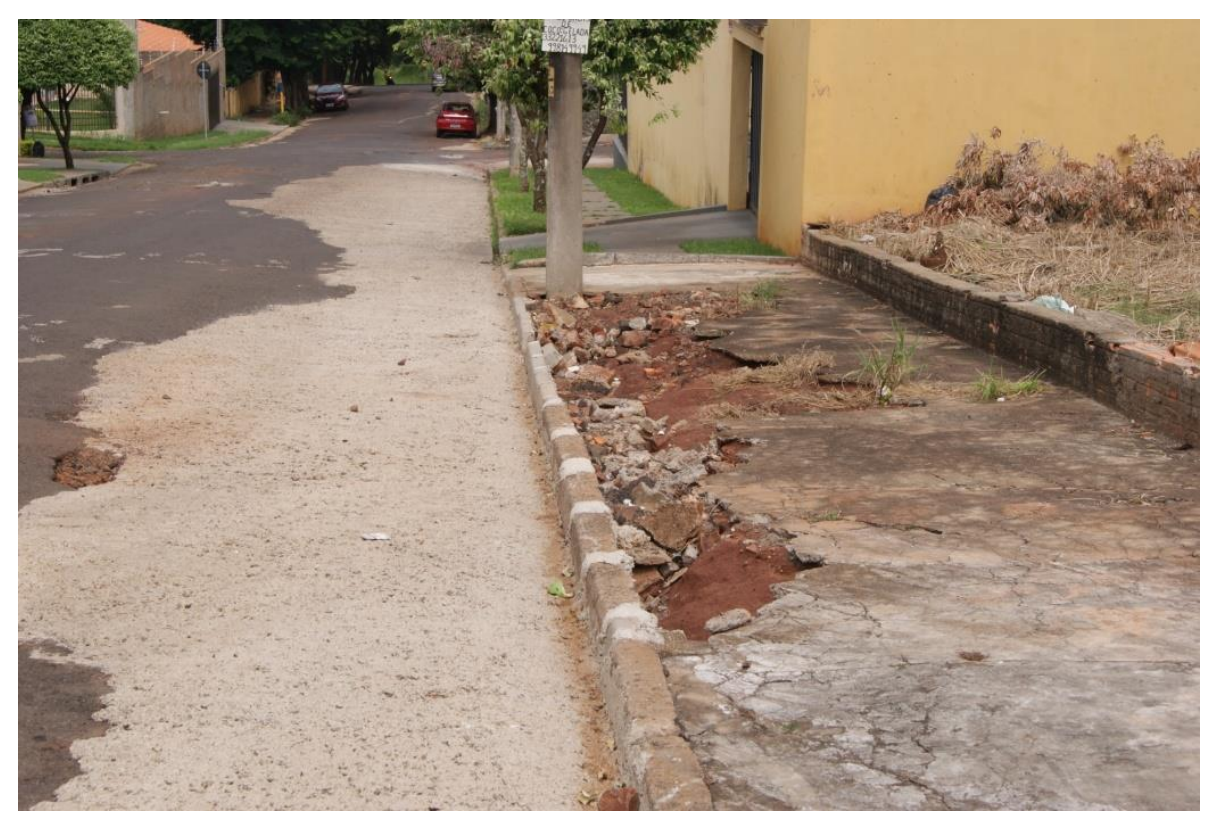

Fotografia dos autores, 2015.

$\mathrm{Na}$ arcada social, pode-se constatar que o problema não é isolado, sendo um costume cultural, pois este hábito é verificado em toda a cidade, não apenas no bairro alvo da pesquisa. Ao praticar o ato de depositar o lixo em vias públicas, o morador demonstra acreditar que a responsabilidade destes resíduos, tanto do lixo doméstico, quanto dos resíduos provenientes de restos de podas, cortes de grama e de construções, assim que saem do portão deixam de ser um problema dele e passam a ser do poder público. Neves et al (2003) "afirma que no caso de resíduos sólidos o aumento da produção não significaria prejuízo ambiental se não fossem as questões relativas às deficiências nos serviços e má conscientização da população".

Este hábito, além dos fatores previamente citados, também traz comprometimento e desgaste da paisagem da cidade, tornando-a feia e deixando com um aspecto sujo. Traz ainda perigo aos pedestres que muitas vezes, tem que desviar dos entulhos e andar no meio da rua, correndo o risco de atropelamentos, arrisca também acidentes aos motoristas, que precisam desviar dos montes posicionados na rua. 
Um dos fatores que levam a esta situação é a crença de que ao colocar esses resíduos na rua, o morador está fazendo um favor à prefeitura e aos serviços de coleta, pois acredita que facilita o recolhimento, que normalmente demora a ocorrer, devido à deficiência da prefeitura em realiza-la. Além disso, a presença de montes de entulhos induz pessoas despreocupadas com a questão ambiental ou desconhecedoras das consequências destes atos, a jogar mais lixo sobre os mesmos, ampliando os riscos e renovando os ciclos de enxurradas e inundações.

Um ponto a ser destacado com relação à quantidade de restos de podas nos depósitos, é que este se trata de um material orgânico de fácil decomposição, que poderia ser destinado à compostagem ao invés de ir para depósitos de lixo comuns.

\section{CONCLUSÃO}

A partir do método de levantamento e análise utilizado neste trabalho se pode observar que em todas as ruas da área estudada se encontravam presentes os depósitos de resíduos ao longo do seu eixo, e que a maioria dos materiais se constituía de restos de poda e de construção.

Observou-se que o problema deriva de um hábito da população, e para ser diminuído deve ser feito um trabalho de conscientização nas residências, nas escolas, centros comunitários, entre outros locais, explicando os problemas e as consequências dessas deposições irregulares. Nesta atividade deve ser destacada a importância de cada indivíduo na manutenção das condições ambientais que permitem o aumento da infiltração da água e a diminuição da sua contaminação e do seu desperdício, condições fundamentais para a recuperação dos aquíferos e aumento da água superficial, mantendo sua perenidade.

A prefeitura deve adotar sistemas de coleta semanal, com dia fixo e divulgar a população para que esta acondicione os materiais adequadamente até o dia do recolhimento desses materiais.

Além disso, deve ser criada legislação específica para no caso das campanhas de conscientização não surtirem efeito, haver a punição dos indivíduos que descumprirem as normas. Lembrando-se que a postura errada de alguns moradores pode trazer consequências nefastas tanto para o ambiente como para toda a sociedade. 


\section{Periódica Eletranica

\section{REFERÊNCIAS BIBLIOGRAFICAS}

CADORIN, Danielle Acco; MELLO, Nilvania Aparecida. Efeitos da impermeabilização dos solos sobre a arborização no município de pato branco-pr. Synergismuss cyentifica UTFPR, Pato Branco, 2011.

JACOBI, Pedro Roberto; BESEN, Gina Rizpah. Gestão de resíduos sólidos em São Paulo: desafios da sustentabilidade. Estudos avançados. São Paulo, v. 25, n. 71, 2011.

NEVES, Marllus Gustavo Ferreira Passos das; TUCCI, Carlos E. M. Gerenciamento integrado em drenagem urbana: quantificação e controle de resíduos sólidos. XV Simpósio Brasileiro de Recursos Hídricos, 2003. Disponível em <http://4ccr.pgr.mpf.mp.br/institucional/grupos-detrabalho/encerrados/residuos/documentos-diversos/outros documentos tecnicos/curso-gestao-doterrimorio-e-manejo-integrado-das-aguas-urbanas/gerresiduo.pdf > Acesso em 25/05/2015

PEDRON, Fabrício de Araújo et al. Solos urbanos. Ciência Rural, Santa Maria, v.34, n.5, p.16471653, set-out, 2004.

PIROLI, Edson Luís. Geoprocessamento aplicado ao estudo da evolução do uso da terra e seus impactos sobre a infiltração de água em microbacias hidrográficas. SBEA, CONBEA, 2014.

OLIVEIRA, Edieliton Gonzaga de; MENDES, Osmar. Gerenciamento de resíduos da construção civil e demolição: estudo de caso da resolução 307 do Conama. Goiania, 2008. Disponível em: <http://www.pucgoias.edu.br/ucg/prope/cpgss/ArquivosUpload/36/file/Continua/GERENCIAMENTO\%2 ODE\%20RES\%C3\%8DDUOS\%20DA\%20CONSTRU\%C3\%87\%C3\%830\%20CIVIL\%20E\%20DEMO LI\%C3\%87\%C3\%830\%20\%20ESTUDO $\% 20$ DE $\% 20$ CASO $\% 20 D A \% 20 R E S O L \quad$.pdf> Acesso em $17 / 04 / 2015$.

TAKENAKA, Edilene Mayumi Murashita et al. Construção civil e resíduos sólidos: coleta e disposição final no município de Presidente Prudente-SP. VIII Fórum Ambiental da Alta Paulista, v.8, n.12, 2012, p.177-186. Disponível em <http://amigosdanatureza.org.br/publicacoes/index.php/forum ambiental/article/view/363/371 > Acesso em 17/04/2015.

TUCCI, Carlos E. M. Plano diretor de drenagem urbana: princípios e concepção. RBRH - Revista Brasileira de Recursos Hídricos, Volume 2 n.2 Jul/Dez 1997, 5-12. Disponível em $<$ http://www.abrh.org.br/sgcv3/UserFiles/Sumarios/db01fdcd78c5843f024709a1bf2b7bdb 6f0118d184 384e38afda2b400a5d6458.pdf> Acesso em 25/05/2015. 